\title{
Actuación de enfermería ante un paciente con infección aguda por el virus de la hepatitis $C$ en hemodiálisis en tratamiento con antivirales de acción directa
}

\author{
Antonio López González, Teresa Pérez López, Lorena Díaz Rodríguez \\ Servicio de Nefrología. Hospital Universitario. A Coruña. España
}

\section{Introducción}

El virus de la hepatitis C (VHC) fue identificado en 1989 por Michael Houghton y se consideró como el origen de la mayoría de las hasta entonces denominadas hepatitis no-A no- $\mathrm{B}^{1,2}$. A día de hoy, constituye un problema de salud pública de gran magnitud en todo el mundo dado su alta prevalencia y elevada evolución hacia la cronicidad, convirtiéndose en una de las principales causas de trasplante hepático ${ }^{3}$.

La incidencia y prevalencia de la infección por VHC entre los pacientes sometidos a hemodiálisis a menudo es mayor que en la población en general ${ }^{4}$. A pesar de que el control de la infección intrahospitalaria ha mejorado gracias a las múltiples líneas de investigación dirigidas a optimizar las medidas de bioseguridad, el alto riesgo de sufrir daño hepático progresivo, cirrosis, fallo hepático o carcinoma hepatocelular, convierten a este virus en todo un desafío para las políticas sanitarias ${ }^{5}$.

En respuesta a esto, en los últimos años, el avance en la investigación farmacéutica ha provocado que el afrontamiento terapéutico del VHC haya evolucionado cambiando completamente el pronóstico de la infección en la población general. El desarrollo de antivirales de acción directa sobre la replicación viral (AAD) ha dejado a un lado el tratamiento estándar con Interferón Pegilado y Ribavirina caracterizado por sus efectos adversos ${ }^{6}$.

\section{Correspondencia:}

Antonio López González

Unidad de Diálisis. Hospital Universitario A Coruña

Xubias de Arriba, 84. 15006 A Coruña

E-mail: Antonio.lopez.gonzalez@sergas.es
En hemodiálisis, a pesar de que se han evidenciado resultados esperanzadores, la experiencia con los AAD es muy reducida.

Por tanto, el objetivo de este artículo es valorar el plan de cuidados de enfermería diseñado para un paciente con infección aguda por VHC en programa de hemodiálisis en tratamiento con AAD.

\section{Caso clínico}

Varón de 69 años diagnosticado en 2003 de Enfermedad Renal Crónica Grado V de etiología no filiada con inicio en programa de hemodiálisis en ese mismo año. Trasplante renal de donante cadáver (2004) con debut diabético e infección por citomegalovirus como complicaciones post-trasplante. Cese funcional del injerto y reinclusión en hemodiálisis en 2015. Otros antecedentes: Vitíligo generalizado, hiperucemia, neumonía y shock séptico, intervenido de hernia inguinal izquierda y hernia discal L4-L5.

Tras analítica ordinaria, se detecta Ac-HVC positivo con VHC RNA PCR positivo (5.89 log UI/ml) y alteración en enzimas hepáticas sin identificación de la causa de seroconversión. Presenta serologías previas negativas para VHC. Se activa aislamiento en hemodiálisis y es derivado a consulta de digestivo para valorar opciones de tratamiento.

Tras detección de genotipo y subtipo (VHC Ib) y evaluación del grado de fibrosis a través de Elastografía hepática (Fibroscan ${ }^{\circledast} 9,2 \mathrm{kPa}$ ), comienza terapia con Ombitasvir/Paritaprevir/Ritonavir $\left(\right.$ Viekirax $\left.^{\circledR}\right)$ y dasabuvir (Exviera ${ }^{\circledR}$ ) durante 12 semanas.

Con una adherencia al tratamiento del $100 \%$, tras cuatro semanas con AAD, no se detectó carga viral de VHC y las enzimas hepáticas se normalizaron. Se retira aislamiento a las 24 semanas de respuesta viral sostenida. 
La descompensación de la tensión arterial en las primeras semanas, la presencia de astenia, ligera trombopenia y descenso de la hemoglobina fueron las principales complicaciones, y se requirió cambio en el tratamiento antihipertensivo y modificación de posología del quelante de fósforo por posible interacción con AAD.

\section{Plan de cuidados de enfermería}

Para la elaboración del plan de cuidados se hizo una valoración del paciente según los patrones funcionales de Majory Gordon al inicio del tratamiento con AAD, reevaluándose una vez finalizado el tratamiento farmacológico.

\section{Valoración inicial:}

\section{Patrón 1: Mantenimiento-Percepción de la Salud.}

Es conocedor del proceso patológico que padece, sin embargo, no tiene claro su repercusión en su estado de salud. No entiende el origen de la situación, pues no refiere hábitos tóxicos ni prácticas que supongan un aumento del riesgo de contagio. Es conocedor del plan de tratamiento pero desconoce sus posibles complicaciones.

\section{Patrón 2: Nutricional y Metabólico.}

Dieta baja en sodio y potasio con ingesta de líquidos reducida a 500 mililitros de agua. Transgrede en muy pocas ocasiones las recomendaciones dietéticas. Presenta ligeros edemas en miembros inferiores. Ganancia de peso interdiálisis de 2 kilogramos.

\section{Patrón 3: Eliminación.}

Paciente en anuria con hábito intestinal regular (una deposición al día).

\section{Patrón 4: Actividad - Ejercicio físico.}

Realiza actividades habituales de forma independiente. Su ejercicio principal se basa en caminatas de 40 minutos con una frecuencia de 3-4 días semana.

\section{Patrón 5: Sueño - Descanso.}

Problemas para conciliar el sueño motivado por la presencia de discopatía y pensamientos sobre su situación de salud. Refiere cansancio desde que comenzó el tratamiento con hemodiálisis.

\section{Patrón 6: Cognitivo- Perceptual.}

Consciente y orientado. No presenta dificultad para el entendimiento de la información proporcionada.

\section{Patrón 7: Autopercepción- Autoconcepto.}

Refiere miedo por la situación actual y la repercusión que pueda tener en la posibilidad de trasplante de donante vivo.

\section{Patrón 8: Rol y Relaciones.}

Vive con su pareja convaleciente de un episodio de accidente cerebrovascular con secuelas en la deambulación y en el habla. Es el cuidador principal y realiza las tareas del hogar. Apoyo familiar disminuido, ya que su única hija y demás familiares viven en otra ciudad.

\section{Patrón 9: Sexualidad - Reproducción.}

Niega contagio por vía sexual

\section{Patrón 10: Adaptación y Tolerancia al estrés.}

Refiere estar preocupado por la situación actual y por el impacto que puede suponer en el cuidado de su mujer.

\section{Patrón 11: Valores - Creencias. \\ Religión Cristiana pero no practicante.}

Tras la valoración inicial se identificaron siete diagnósticos enfermeros utilizando la taxonomía NANDA7; se fijaron los resultados NOC8 y sus indicadores de resultado, los cuales se valoraron al inicio y al final del tratamiento con AAD mediante una escala Likert, y se establecieron las intervenciones NIC9 (Tabla 1).

Una vez finalizado el tratamiento farmacológico a las 12 semanas, con una adherencia del $100 \%$, el paciente se encontró más tranquilo, confiado y agradecido.

Tras la intervención en la crisis inicial, explicándole su situación y proporcionándole apoyo emocional mediante escucha activa en cada sesión de hemodiálisis, se consiguió al final del tratamiento, puntuaciones en la escala Likert muy superiores a las registradas al inicio del tratamiento, en todos los indicadores de resultado utilizados, tal y como se muestra en la Tabla 1. 
Actuación de enfermería ante un paciente con infección aguda por el virus de la hepatitis C en hemodiálisis en tratamiento...

Tabla 1. Diagnósticos de enfermería (taxonomía NANDA) con los criterios de resultados (taxonomía NOC) e intervenciones (taxonomía NIC) durante el tratamiento con AAD.

00069- Afrontamiento inefectivo, relacionado con falta de confianza en la capacidad de afrontar la situación e incertidumbre, manifestado por expresiones de incapacidad para satisfacer las expectativas del rol.

\section{RESULTADOS NOC}

INDICADORES

INTERVENCIONES NIC
1302- Afrontamiento de problemas

130204- Refiere disminución de estrés.

130210- Adopta conductas para reducir el estrés.

130205- Verbaliza aceptación de la situación.

130218- Refiere un Aumento del bienestar psicológico.

4920- Escucha Activa.

- Aclarar el mensaje mediante el uso de preguntas y retroalimentación.

- Mostrar interés por el paciente.

5230- Aumentar el afrontamiento.

- Alentar las manifestaciones de sentimientos, percepciones y miedos.

- Ayudar al paciente a clarificar los conceptos equivocados.

-Ayudar al paciente a identificar objetivos adecuados a corto y largo plazo.

\section{0- Apoyo emocional.}

- Ayudar al paciente a que exprese los sentimientos de ansiedad, ira o tristeza.

- Favorecer la conversación o el llanto como miedo de disminuir la respuesta emocional.
RESULTADOS NOC

INDICADORES

INTERVENCIONES NIC
1402- Autocontrol de la ansiedad.

1404- Autocontrol del miedo.

140217- Controla la respuesta de ansiedad.

140410- Mantiene la realización del rol.

140417- Controla la respuesta del miedo.

5820 Disminución de la ansiedad.

- Proporcionar información objetiva respecto del diagnóstico, tratamiento y pronóstico.

- Escuchar con atención.

- Crear ambiente que facilite la confianza.

- Identificar los cambios en el nivel de ansiedad.

- Instruir al paciente sobre el uso de técnicas de relajación.

000162- Disposición para mejorar la gestión de la propia salud, relacionado con complejidad del tratamiento y déficit de conocimientos, manifestado por deseos de manejar el tratamiento de la enfermedad.

RESULTADOS NOC

INDICADORES
1808- Conocimiento: Medicación.

1813- Conocimiento: Régimen Terapéutico.

180810- Descripción de la administración correcta de la medicación.

180814- Descripción de cómo obtener la medicación y suministros requeridos.

180805 - Descripción de los efectos indeseables de la medicación.

181310 - Descripción de la medicación prescrita.

\begin{tabular}{|c|c|}
\hline $\begin{array}{c}\text { Escala Likert } \\
\text { Inicio }\end{array}$ & $\begin{array}{c}\text { Escala Likert } \\
\text { Final }\end{array}$ \\
2 & 5 \\
3 & 5 \\
3 & 4 \\
\hline
\end{tabular}

la Likert
Final
4
5
5
4


Actuación de enfermería ante un paciente con infección aguda por el virus de la hepatitis C en hemodiálisis en tratamiento...

INTERVENCIONES NIC
5616- Enseñanza: Medicamentos Prescritos.

- Informar al paciente tanto del nombre genérico como del comercial de cada medicamentos.

- Informar al paciente del propósito y acción de cada medicamento.

- Instruir al paciente acerca de la dosis, vía y duración de los efectos de cada medicación.

- Informar al paciente sobre lo que tiene que hacer si se pasa por alto una dosis.

- Instruir al paciente acerca de los posibles efectos secundarios adversos de cada medicamento.

- Informar al paciente sobre posibles interacciones de fármacos/comidas.

\section{0 - Manejo de la Medicación.}

- Observar si hay signos y síntomas de toxicidad de loa medicación.

- Observar si se producen efectos adversos derivados de los fármacos.

- Determinar los factores que pueden impedir al paciente tomar los fármacos tal como se han prescrito.

00092- Intolerancia a la actividad, relacionado con debilidad generalizada, manifestado por informes verbales de debilidad

RESULTADOS NOC

INDICADORES

INTERVENCIONES NIC
0001- Resistencia.

0005 - Tolerancia actividad.

000101- Realización de la rutina habitual

000518- Facilidad para realizar las actividades de la vida diaria (AVD).

\begin{tabular}{|c|c|}
\hline $\begin{array}{c}\text { Escala Likert } \\
\text { Inicio }\end{array}$ & $\begin{array}{c}\text { Escala Likert } \\
\text { Final }\end{array}$ \\
2 & 5 \\
3 & 5 \\
\hline
\end{tabular}

4310-Terapia de actividades.

- Ayudar a elegir actividades coherentes con sus posibilidades físicas, psicológicas y sociales.

- Explicar el papel de la actividad física, social y cognitiva en el mantenimiento de la funcionalidad y la salud.

4420- Acuerdo con el paciente.

- Ayudar al paciente a establecer objetivos realistas, que puedan conseguirse.

- Ayudar al paciente a desarrollar un plan para cumplir los objetivos.

00095-Deterioro del patrón de sueño, relacionado con pensamientos reiterados antes del sueño, manifestado por quejas verbales de dificultad para conciliar el sueño.

RESULTADOS NOC

INDICADORES

INTERVENCIONES NIC
0004- Sueño.

000403- Patrón del sueño.

000404- Calidad de sueño.

\begin{tabular}{|c|c|}
\hline $\begin{array}{c}\text { Escala Likert } \\
\text { Inicio }\end{array}$ & $\begin{array}{c}\text { Escala Likert } \\
\text { Final }\end{array}$ \\
3 & 4 \\
1 & 5 \\
\hline
\end{tabular}

1850 - Mejorar el sueño.

- Determinar el esquema de sueño / vigilia del paciente.

- Establecer una rutina a la hora de irse a la cama que facilite la transición del estado de vigilia al de sueño.

- Ayudar al paciente a limitar el sueño durante el día disponiendo una actividad que favorezca la vigilia.

- Comentar con el paciente técnicas para favorecer el sueño.

\section{5 - Riesgo de desequilibrio de volumen de líquidos, relacionado con ingesta de líquido y pérdida de peso magro.}

RESULTADOS NOC

INDICADORES
0601- Equilibrio hídrico.

1902- Control de Riesgo.

060112- Edema periférico.

060101- Presión arterial.

190208- Modifica el estilo de vida para reducir el riesgo.

190216- Reconoce cambios en el estado de salud.

\begin{tabular}{|c|c|}
\hline $\begin{array}{c}\text { Escala Likert } \\
\text { Inicio }\end{array}$ & $\begin{array}{c}\text { Escala Likert } \\
\text { Final }\end{array}$ \\
1 & 5 \\
3 & 5 \\
3 & 4 \\
3 & 5 \\
\hline
\end{tabular}




\begin{tabular}{|c|c|c|c|}
\hline INTERVENCIONES NIC & \multicolumn{3}{|c|}{$\begin{array}{l}\text { 4120- Manejo de líquidos. } \\
\text {-Pesar a diario y controlar la evolución. } \\
\text {-Observar signos de sobrecarga de líquidos. } \\
\text {-Realizar un registro preciso de ingesta y eliminación. } \\
\text {-Vigilar el estado de hidratación (membranas mucosas, pulso adecuado y presión sanguínea ortos- } \\
\text { tática). } \\
\text {-Controlar los cambios de peso antes y después de la diálisis; Monitorizar signos vitales, si procede. } \\
\text {-Monitorizar el estado nutricional. }\end{array}$} \\
\hline \multicolumn{4}{|c|}{$\begin{array}{l}\text { 00004- Riesgo de infección relacionado con disminución de defensas segundarias (descenso de hemoglobina) y enfermedad } \\
\text { crónica. }\end{array}$} \\
\hline RESULTADOS NOC & \multicolumn{3}{|l|}{$\begin{array}{l}\text { 1004-Estado Nutricional. } \\
\text { 1902- Control del Riesgo. }\end{array}$} \\
\hline \multirow{3}{*}{ INDICADORES } & & $\begin{array}{l}\text { Escala Likert } \\
\text { Inicio }\end{array}$ & $\begin{array}{l}\text { Escala Likert } \\
\quad \text { Final }\end{array}$ \\
\hline & 100401- Ingestión de nutrientes. & 3 & 4 \\
\hline & 190201- Reconoce el riesgo. & 3 & 4 \\
\hline & \multicolumn{3}{|c|}{$\begin{array}{l}\text { 1100.- Manejo de la nutrición. } \\
\text { - Fomentar una ingesta nutricional suficiente. } \\
\text { - Ajustar la dieta al estilo de vida del paciente. } \\
\text { - Asegurar que la dieta incluye alimentos ricos en fibra para evitar el estreñimiento. } \\
\text { - Determinar la capacidad del paciente para satisfacer las necesidades nutricionales. }\end{array}$} \\
\hline INTERVENCIONES NIC & \multicolumn{3}{|c|}{$\begin{array}{l}\text { 6550- Protección contra las infecciones. } \\
\text { - Observar los signos y síntomas de infección sistemática y localizada. } \\
\text { - Observar el grado de vulnerabilidad del/de la paciente las infecciones. } \\
\text { - Facilitar el descanso. } \\
\text { - Observar si hay cambios en el nivel de vitalidad /malestar. } \\
\text { - Instruir al paciente sobre los signos y síntomas de infección y cuando deben informar de ellos. }\end{array}$} \\
\hline
\end{tabular}

\section{Discusión}

El cambio de panorama en el manejo terapéutico del VHC con el empleo de los AAD constituye un avance esperanzador. Aunque la experiencia con esta terapia en hemodiálisis es reducidal0, los resultados disponibles evidencian una gran eficacia con mínimos efectos adversos como se observa también en nuestro caso.

A pesar de ello, la hepatitis $C$, sigue provocando un gran impacto emocional en la persona afectada y en su entorno. La preocupación, ansiedad y el miedo, junto con una necesidad imperiosa comprender y saber más sobre la enfermedad, no sólo dificultan la evolución del proceso patológico sino que conforman un nuevo problema, que en muchos casos impide que la persona pueda afrontar este proceso de manera efectiva. Esta situación se vio reflejada en nuestro caso. Sin embargo, mediante una intervención adecuada creando un espacio de escucha para proporcionar seguridad, aceptación y ánimo, favoreciendo la expresión de los sentimientos y pensamientos, se ha conseguido una mejora en el afrontamiento a la nueva situación clínica.
Por tanto, es imprescindible destacar que el avance farmacológico ha de ir acompañado de un abordaje multidisciplinar en el que la enfermería juega un papel fundamental, ya que el contacto continuo con el paciente genera una relación de cercanía y confianza que facilita la intervención sobre la esfera emocional, pilar fundamental para garantizar una óptima adherencia al tratamiento y un mínimo impacto en la calidad de vida del paciente ${ }^{11-15}$.

\section{Conclusiones}

El uso de lenguaje estandarizado, aplicando las taxonomías enfermeras posibilita la normalización de la práctica enfermera y consecuentemente la unificación de criterios para poder identificar los problemas, las necesidades de los pacientes y poder realizar las intervenciones adecuadas.

En este caso, la identificación de un afrontamiento ineficaz y el consiguiente diseño de estrategias para el manejo emocional que implicaron la habituación del 
paciente a responsabilidades respecto de la toma de medicamentos y cambios del estilo de vida, fueron fundamentales para garantizar el éxito de la terapia.

\section{El autor declara que no hay conflicto de interés.}

Recibido: 25 agosto 2017

Revisado: 15 septiembre 2017

Modificado: 24 septiembre 2017

Aceptado: 5 octubre 2017

\section{Bibliografía}

1. Sánchez-Tapias JM. Hepatitis crónica por el virus de la hepatitis C. En: Berenguer Lapuerta $\mathrm{J}$ et al, editores. Tratamiento de las enfermedades hepáticas y biliares. Madrid: Asociación Española para el Estudio del Hígado; 2001.

2. U.S. Department of Health and Human Services. National Institutes of Health Consensus Conference Statement: Management of Hepatitis C. Hepatology. 2002; 36(5): 3-20.

3. Goodkin DA, Bieber B, Gillespie B, Robinson $B M$, Jadoul M. Hepatitis $C$ infection is very rarely treated among hemodialysis patients. Am J Nephrol. 2013; 38: 405-412.

4. Health Advisory CDC: CDC Urging Dialysis Providers and Facilities to Assess and Improve Infection Control Practices to Stop Hepatitis C Virus Transmission in Patients Undergoing Hemodialysis. 2016.

5. Goodkin DA, Bieber B, Jadoul M, Martin P, Kanda E,Pisoni RL. Mortality, Hospitalization, and Quality of Life among Patients with Hepatitis C Infection on Hemodialysis. Clin J Am Soc Nephrol.2017; 12: 287-297.

6. Russo MW, Goldsweig CD, Jacobson IM, Brown RS Jr. Interferon monotherapy for dialysis patients with chronic hepatitis C: An analysis of the literature on efficacy and safety. Am J Gastroenterol. 2003;98: 1610-5.

7. Herdman $\mathrm{TH}$, editor. NANDA International. Diagnósticos enfermeros: definiciones y clasificación 2015-2017. Madrid: Elsevier; 2015.

8. Moorhead S, Johnson M, Mass M, Swanson E. Clasificación de resultados de enfermería (NOC): Medición de Resultados en Salud. $5^{\text {a }}$ ed. Madrid: Elsevier; 2014.

9. Bulecheck GM, Butcher HK, Dochterman JM, Wagner CM. Clasificación de Intervenciones de Enfermería (NIC). 6 ${ }^{a}$ ed. Madrid: Elsevier; 2014.

10. Abad S, Vega A, Rincón D, Hernández E, Mérida E, Macíasa $N$, et al. Eficacia de los antivirales de acción directa en la infección por el virus de la hepatitis $C$ en pacientes en hemodiálisis. Nefrología. 2017; 37 (2):158-163.

11. Ojeda Ramírez MD, Caro Rodríguez I, Ojeda Ramírez D, García Pérez A, García Hita S, García Marcos S. Consulta de enfermería y adherencia terapéutica del paciente en hemodiálisis. Enferm Nefrol. 2017; 20 (2): 132-138.

12. Ruiz García E, Latorre López LI, Delgado Ramírez A, Crespo Montero R, Sánchez Laguna $\mathrm{JL}$. Adherencia al tratamiento farmacológico en pacientes en hemodiálisis. Enferm Nefrol. 2016; 19 (3): 232-241.

13. Vázquez Espinoza JA, Velasco Rodríguez $R$, Alcaraz Moreno N, Pérez Hernández MG, Casique Casique L. Apoyo educativo y patrón de vida en el paciente con tratamiento de hemodiálisis. Enferm Nefrol. 2017; 20 (1): 28-36.

14. Torres Torradeflot MC, Gutiérrez Vilaplana JM, Craver L, Baigol Guilanya M. Resultado de la intervención Enseñanza: Dieta prescrita en la consulta de enfermedad renal crónica avanzada. Enferm Nefrol. 2016; 19 (1): 12-19.

15. Cuevas-Budhart MA, Saucedo García RP, Romero Quechol G, García Larumbe JA, Hernández P, Puente A. Relación entre las complicaciones y la calidad de vida del paciente en hemodiálisis. Enferm Nefrol. 2017; 20 (2): 112-119.

Este artículo se distribuye bajo una Licencia Creative Commons Atribución-NoComercial 4.0 Internacional.

https://creativecommons.org/licenses/by-nc/4.0/

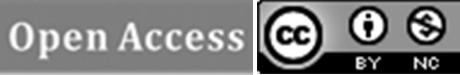

